\title{
Inhibition of erythrocyte 5-aminolaevulinate hydrolyase activity by tin and its prevention by selenite
}

\author{
Momoko Chiba, Atsuko Shinohara
}

\begin{abstract}
Mice were injected with either $\mathbf{S n C l}_{2}$ (intraperitoneal) or $\mathrm{Na}_{2} \mathrm{SeO}_{3}$ (subcutaneous) alone or together at doses of $50 \mu \mathrm{mol} / \mathrm{kg}$ body weight. After 20 hours blood was collected and the concentrations of tin ( $\mathrm{Sn}$ ) and Selenium (Se) and the activity of 5-aminolaevulinate hydrolyase (ALA dehydratase, EC 4.2.1.24) in blood were determined. The concentrations of $\mathrm{Sn}$ in whole blood were $4.9($ SD 1.5$) \mathrm{nmol} / \mathrm{ml}$ $(n=4)$ and ALA dehydratase activity was $10 \%$ of the control in Sn treated animals. Concentrations of Sn were 2.6 (SD 0.6) $\mathrm{nmol} / \mathrm{ml}$ and ALA dehydratase activity was $92 \%$ of that in control animals when $\mathrm{Sn}$ and $\mathrm{Se}$ were simultaneously injected. The supernatant from lysed erythrocytes from Sn treated mice were applied to a Sephacryl S-300 column. The predominant peak containing Sn was eluted at the position of haemoglobin; a second peak was eluted at the position of ALA dehydratase. When the supernatant of lysed erythrocytes from mice injected with $S n$ and $S e$ was chromatographed, a negligible amount of Sn was detected in the ALA dehydratase fraction. It thus appears that $\mathrm{Sn}$ binds to ALA dehydratase molecules and inhibits enzyme activity, and that simultaneous injection of Se prevents Sn binding to ALA dehydratase, thereby preventing the inhibition of ALA dehydratase activity by $\mathbf{S n}$.
\end{abstract}

It has been reported that in animals tin (Sn) is an essential element. ${ }^{1}$ Little research on the biological role and effect of this element on organisms has, however, been carried out. One reason is that $\mathrm{Sn}$ is a difficult element to quantify at concentrations below one part per million. Recently an improved method

Department of Hygiene, Juntendo University School of Medicine, Tokyo 113, Japan

M Chiba, A Shinohara for measurement of $\mathrm{Sn}$ in biological materials has been developed. This allows concentrations as low as $0.04 \mathrm{ng}$ to be accurately determined. ${ }^{2}$

Toxic effects of inorganic $\mathrm{Sn}$ include vulnerability of the femoral bone to external compressive force in rats, ${ }^{3}$ disturbance of porphyrin biosynthesis in rabbits $^{4}$ and mice, ${ }^{5}$ and growth retardation in rats. ${ }^{6}$ Recently agricultural and industrial use of organic $\mathrm{Sn}$ has increased with a concomitant increased human exposure to $\mathrm{Sn}$.

In this report we have focused on the effect of inorganic $\mathrm{Sn}$ on the porphyrin biosynthetic pathway. 5 -Aminolaevulinate hydrolyase $(\delta$-aminolaevulinic acid dehydratase, ALA dehydratase, EC 4.2.1.24) is the second enzyme in porphyrin biosynthesis, and is a sulphydryl enzyme with an estimated molecular weight of $2.5 \times 10^{5}$ daltons. ${ }^{7}$ It is well known that ALA dehydratase activity in blood is inhibited by lead $(\mathrm{Pb})$ and the inhibition of this enzyme activity is the earliest sign of a body burden of $\mathrm{Pb}^{8}{ }^{8}$ The effects of various metals on erythrocyte ALA dehydratase activity were examined and it was shown that $\mathrm{Sn}$ as well as $\mathrm{Pb}$ had a strong inhibitory effect on ALA dehydratase activity. ${ }^{9}$ It is known that sodium selenite counteracts the toxic effects of mercury ${ }^{10}$ and cadmium. ${ }^{11}$ Sodium selenite $\left(\mathrm{Na}_{2} \mathrm{SeO}_{3}\right)$, when administered simultaneously with $\mathrm{Sn}$, prevented the inhibition of ALA dehydratase activity caused by $\mathrm{Sn}$. No effect of sodium selenite was seen, however, with respect to ALA dehydratase inhibition by $\mathrm{Pb} .^{12}$ To investigate the mechanism of interaction between $\mathrm{Sn}$ and seleniun ( $\mathrm{Se}$ ), the binding proteins of $\mathrm{Sn}$ were chromatographed, and their modification by selenite was examined.

\section{Materials and methods}

\section{ANIMALS}

Four week old male ICR mice were purchased (Nippon Biosupply Centre, Tokyo) and housed for one week in a climatic chamber maintained at 25 (SD $0.5)^{\circ} \mathrm{C}$ and 60 (SD 5)\% relative humidity. They were given standard laboratory chow (EC-2, Clea Japan Inc, Tokyo) and distilled water ad libitum. Four groups of mice were used for this experiment; group 
A served as control, group B were administered $\mathrm{Sn}$ alone, group C selenite alone, and group D Sn plus selenite.

\section{TREATMENTS}

Stannous chloride $\left(\mathrm{SnCl}_{2}\right.$, Koso Chemical $\mathrm{Co}$, Tokyo) or sodium selenite $\left(\mathrm{Na}_{2} \mathrm{SeO}_{3}\right.$, Wako Pure Chemical Industries Ltd, Osaka) were dissolved in $5 \%$ glucose solution to make concentrations of $5 \mu \mathrm{mol} / \mathrm{ml} \mathrm{Sn}$ or Se. These solutions were administered at $0.1 \mathrm{ml}$ per $10 \mathrm{~g}$ of body weight, doses corresponding to $50 \mu \mathrm{mol}$ of each element per kg body weight. The $\mathrm{SnCl}_{2}$ solution was always injected intraperitoneally and the $\mathrm{Na}_{2} \mathrm{SeO}_{3}$ solution subcutaneously. In group $\mathrm{D}$ ( $\mathrm{Sn}$ plus $\mathrm{Se}$ ) $\mathrm{Na}_{2} \mathrm{SeO}_{3}$ was given immediately after $\mathrm{SnCl}_{2}$ administration. Sodium selenite solution in group B (Sn alone) and $\mathrm{SnCl}_{2}$ solution in Group C (Se alone) were replaced with $5 \%$ glucose solution. Twenty hours after the injections animals were anaesthetised with diethyl ether and blood was drawn from the femoral vein.

\section{PREPARATION AND GEL CHROMATOGRAPHY OF BLOOD SAMPLES}

The blood was centrifuged at $3000 \mathrm{~g}$ for five minutes to separate erythrocytes from plasma. The erythrocytes were then rinsed with $5 \%$ glucose solution twice and stored in a freezer at $-80^{\circ} \mathrm{C}$ until use. One $\mathrm{ml}$ of lysed erythrocytes was added to 10 volumes of $10 \mathrm{mM}$ tris $\mathrm{HCl}$ buffer ( $\mathrm{pH} \mathrm{7.4}$ ), and the mixture centrifuged at $9000 \mathrm{~g}$ for 20 minutes. The supernatant fraction was passed through a $0.22 \mu \mathrm{m}$ filter and applied as a $4 \mathrm{ml}$ sample to a column $(1.6 \times 95 \mathrm{~cm})$ packed with Sephacryl S-300. Samples were eluted with $50 \mathrm{mM}$ tris $\mathrm{HCl}$ buffer (pH 7.4) at a flow rate of $12 \mathrm{ml} /$ hour at $4^{\circ} \mathrm{C}$. Aliquots of $2.8 \mathrm{ml}$ were collected per fraction tube.

DETERMINATION OF PROTEIN, HAEMOGLOBIN, Sn, AND Se CONCENTRATIONS, AND ALA DEHYDRATASE ACTIVITY Protein and haemoglobin concentrations were measured by absorbance at $280 \mathrm{~nm}$ and $405 \mathrm{~nm}$ respectively. The concentration of $\mathrm{Sn}$ was determined by atomic absorption spectroscopy with the previously described procedure. ${ }^{2}$ Concentration of

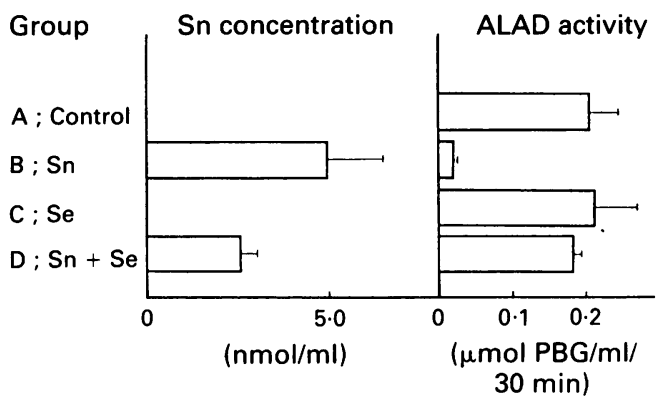

Figure 1 Tin concentration and ALA dehydratase ( $A L A D)$ activity in whole blood.

Se was determined fluorimetorically. ${ }^{13}$ The activity of ALA dehydratase in whole blood was assayed as follows; $320 \mu \mathrm{l}$ haemolysate, which contained blood and nine volumes of demineralised water, $80 \mu \mathrm{l}$ substrate solution containing $250 \mathrm{mM}$ sodium phosphate buffer (pH 6.8), and $25 \mathrm{mM} 5$-aminolaevulinic acid were incubated at $37^{\circ} \mathrm{C}$ for 30 minutes. When ALA dehydratase activity of eluate fractions was assayed, $200 \mu \mathrm{l}$ eluate, $80 \mu \mathrm{l}$ substrate solution, and $120 \mu \mathrm{l}$ demineralised distilled water were incubated. The reaction was stopped by the addition of $0.4 \mathrm{ml}$ $1 \mathrm{M}$ trichloroacetic acid containing $70 \mathrm{mM}$ mercuric chloride. The supernatant $(0.5 \mathrm{ml})$ that resulted from centrifugation at $3000 \mathrm{~g}$ for 5 minutes was added to an equal volume of Ehrlich reagent. The mixture was allowed to stand at room temperature for five minutes, then absorbance at $555 \mathrm{~nm}$ was measured using a Hitachi model 320 spectrophotometer. The ALA dehydratase activity was expressed as $\mu \mathrm{mol}$ porphobilinogen $/ \mathrm{ml} / 30 \mathrm{~min}$.

\section{Results}

Sn AND Se CONCENTRATIONS AND ALA DEHYDRATASE ACTIVITY IN WHOLE BLOOD

Figure 1 shows the $\mathrm{Sn}$ concentration and the ALA dehydratase activity in whole blood. No Sn was detected in the group A (control) and group C (Se alone) mice. The concentration of $\mathrm{Sn}$ was 4.9 (SD 1.5) $\mathrm{nmol} / \mathrm{ml} ; \mathrm{n}=4)$ in group $\mathrm{B}$ (Sn alone). The

Tin and Se concentrations in erythrocytes and plasma

\begin{tabular}{|c|c|c|c|c|}
\hline \multirow[t]{2}{*}{ Group } & \multicolumn{2}{|l|}{$S n(n m o l / m l)$} & \multicolumn{2}{|l|}{$\mathrm{Se}(\mathrm{nmol} / \mathrm{ml})$} \\
\hline & $\begin{array}{l}\text { Erythrocytes } \\
\text { Mean }(S D)\end{array}$ & $\begin{array}{l}\text { Plasma } \\
\text { Mean (SD) }\end{array}$ & $\begin{array}{l}\text { Erythrocytes } \\
\text { Mean }(S D)\end{array}$ & $\begin{array}{l}\text { Plasma } \\
\text { Mean (SD) }\end{array}$ \\
\hline $\begin{array}{l}\text { A: Control }(n=4) \\
\text { B: } \operatorname{Sn}(n=4) \\
\text { C: } \operatorname{Se}(n=4) \\
\text { D: Sn plus } \operatorname{Se}(n=4)\end{array}$ & $\begin{array}{l}\text { ND } \\
11.54(4 \cdot 35) \\
\text { ND } \\
4.98(0 \cdot 76)^{b}\end{array}$ & $\begin{array}{l}\text { ND } \\
0.79(0.23) \\
\text { ND } \\
1.50(0.38)^{b}\end{array}$ & $\begin{array}{c}6.46(0.71) \\
5.67(1.23) \\
50 \cdot 79(12 \cdot 83)^{a b} \\
44.70(9 \cdot 28)^{a b}\end{array}$ & $\begin{array}{l}5.99(0.81) \\
5.23(0.94) \\
6.32(1.81) \\
7.83(0.40)^{2}\end{array}$ \\
\hline
\end{tabular}

a $<0.05$ compared with group A; ${ }^{b}$ p $<0.05$ compared with group $B$.

$\mathrm{ND}=$ Not detected. 
concentrations of Sn declined to $2 \cdot 6$ (SD $0 \cdot 6$ ) nmol/ $\mathrm{ml}(\mathrm{n}=4)$ in group $\mathrm{D}$ (Sn plus Se). These values differed significantly $(p<0.05)$. Activity of ALA dehydratase in the control group was 205 (SD 40) $\mathrm{nmol}$ porphobilinogen $/ \mathrm{ml} / 30 \mathrm{~min}(\mathrm{n}=4)$. The activity was significantly reduced by $\mathrm{Sn}$ to $10 \%$ of the control (20 (SD 5) nmol porphobilinogen $/ \mathrm{ml} / 30 \mathrm{~min}$, $\mathrm{p}<0.05 ; \mathrm{n}=4)$. When $\mathrm{Na}_{2} \mathrm{SeO}_{3}$ was injected together with $\mathrm{SnCl}_{2}$, ALA dehydratase activity was not significantly inhibited (185 (SD 20) nmol porphobilinogen $/ \mathrm{ml} / 30 \mathrm{~min} ; \mathrm{n}=4$ ) compared with controls. Administration of $\mathrm{Na}_{2} \mathrm{SeO}_{3}$ alone did not affect activity of this enzyme.

The table shows the distribution of $\mathrm{Sn}$ and $\mathrm{Se}$ in plasma and erythrocytes. Most of the Sn in blood was found in erythrocytes; $90 \%$ of the Sn was in erythrocytes in group $\mathrm{B}$ (Sn alone) mice, and $69 \%$ in group $\mathrm{D}$ ( $\mathrm{Sn}$ and $\mathrm{Se}$ ). The concentration of $\mathrm{Sn}$ was also determined in the erythrocyte membrane obtained as a precipitate after centrifugation of the lysed erythrocytes. Only $3.1 \%$ and $4.6 \%$ of total $\mathrm{Sn}$ in erythrocytes in groups $B$ and $D$ respectively was contained in the membrane fraction. In the control group, considerable amounts of Se were found in whole blood and the distribution of Se in plasma and erythrocytes (table) was similar to that reported for human blood. ${ }^{14}$ Administered $\mathrm{Se}$ accumulated mainly in erythrocytes. When Se alone was injected, the Se content in erythrocytes increased to 7.9 times the control value, whereas an insignificant change was noted in plasma. When Se was administered together with $\mathrm{Sn}$, Se content in erythrocytes was 6.9 times, and that in plasma 1.3 times the value in the control group. These increases were statistically significant $(\mathrm{p}<0.05)$.

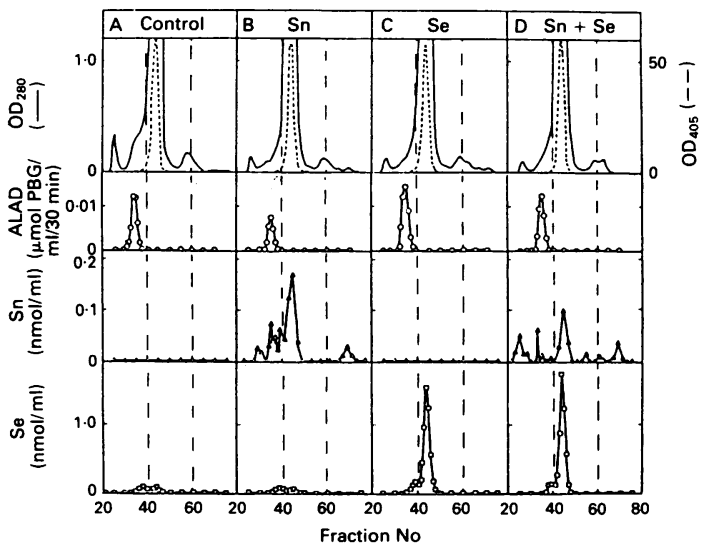

Figure 2 The elution profile of lysed erythrocytes. A: group $A$ (control); B: group B (50 $\mu \mathrm{mol} S \mathrm{Sn} / \mathrm{kg}) ; C:$ group $C$ ( $50 \mu \mathrm{mol} S \mathrm{Se} / \mathrm{kg}$ ); D: group D (Sn plus $\mathrm{Se}$ at the same doses as groups $B$ and $C$ ).
GEL FILTRATION OF LYSED ERYTHROCYTES

Figure 2A shows the elution profile for group A (control). The main protein peak was eluted in fractions 38-46. The haemoglobin peak was also eluted in fractions 42-46. The ALA dehydratase activity appeared in fractions 33-36. There were two Se peaks, in fractions $36-40$ and $42-46$.

Figure 2B shows the elution profile for group B ( $\mathrm{Sn}$ alone). The chromatographic aspects of protein, haemoglobin, and Se concentrations were similar to those of controls. The main Sn peak corresponded to the haemoglobin fraction (fractions 41-47). A second peak was eluted in fractions 33-36, which corresponded to the ALA dehydratase fractions. Minor peaks were also observed. The ALA dehydratase activity was eluted in the same fractions as in the control; however, total enzyme activity was appreciably depressed $(50 \%$ of control).

Figure $2 \mathrm{C}$ shows the elution profile for group $\mathrm{C}$ ( $\mathrm{Se}$ alone); Se was eluted mainly in fractions 42-46, which corresponded to the second Se peak in the control. Injected Se had no effect on the activity of ALA dehydratase.

Figure 2D shows the elution profile for group D ( $\mathrm{Sn}$ plus Se). Total Sn concentration was considerably lower in this group when compared with group $\mathrm{B}$ (Sn alone). Also, the chromatographic profile of $\mathrm{Sn}$ was substantially altered. Most notably, there was no association of $\mathrm{Sn}$ with the ALA dehydratase fractions, a greater amount of $\mathrm{Sn}$ was eluted with the void volume, and three low molecular weight Sn peaks were found instead of the single low molecular weight peak seen in group B. The ALA dehydratase activity was much higher in this group (group D) than in the group treated with Sn alone (group B), and was comparable with that in the control group (group A). With regard to Se concentration, the chromatographic profile was similar to that in group $\mathrm{C}$ (Se alone).

\section{Discussion}

In previous studies we have focused on the inhibition of ALA dehydratase activity in blood as an index of the toxic effect of inorganic $\mathrm{Sn} .{ }^{4512}$ Administration of stannous chloride resulted in the dose dependent inhibition of the activity of erythrocyte ALA dehydratase. Selenite prevented the inhibition of the enzyme activity caused by $\mathrm{Sn}$. The most effective condition was simultaneous injection of the elements at a molar ratio of Se:Sn of more than $1 .{ }^{5} \mathrm{We}$ therefore adopted a dose of $50 \mu \mathrm{mol} / \mathrm{kg}$ body weight of each element in the present study. The elution profiles of the lysed erythrocytes were examined by gel filtration because both $\mathrm{Sn}$ and Se accumulate mainly in erythrocytes and ALA dehydratase is localised in erythrocytes. The ALA dehydratase activity was eluted at fractions $33-36$. This position 
corresponds to a molecular weight of approximately $2.5 \times 10^{5}$ daltons, which is comparable with that reported in previous studies. ${ }^{7}$ In group A (control), which contained no detectable Sn, total ALA dehydratase activity in the eluate was $111 \mathrm{nmol}$ porphobilinogen $/ 30 \mathrm{~min}$. In group $\mathrm{B}$ (Sn alone), total ALA dehydratase activity in the eluate had declined to $57 \mathrm{nmol}$ porphobilinogen $/ 30 \mathrm{~min}$. The results suggest that a part of the administered $\mathrm{Sn}$ was incorporated into ALA dehydratase (fig 2B) and that the $\mathrm{Sn}$ inhibited the enzyme activity. this supression was $51 \%$; however, ALA dehydratase activity in whole blood of mice injected with Sn alone (group B) was reduced to $10 \%$ of the control group (fig 1 ). It is possible that some of the Sn associated with ALA dehydratase might be removed while passing through the column, or that $\mathrm{Sn}$ in the membrane or haemoglobin fractions might affect the activity during the assay procedure. It has been shown by Lineweaver-Bulk plot that Sn inhibits ALA dehydratase activity non-competitively. ${ }^{15}$

In group $\mathrm{D}$, the $\mathrm{Sn}$ concentration of whole blood was one half of group B (fig 1). Thus, Se may prevent $\mathrm{Sn}$ incorporation into blood or may enhance the elimination of $\mathrm{Sn}$ from blood. As a result group D Sn concentrations declined to $50 \%$ in whole blood and $45 \%$ in erythrocytes as compared with group B. The ALA dehydratase activity in eluates of group $D$ ( $S n$ plus Se) was comparable with that in group $\mathrm{A}$ (control) even though a considerable amount of $\mathrm{Sn}$ was present in group D erythrocytes. A negligible amount of $\mathrm{Sn}$ was found in the ALA dehydratase fraction; thus it appears that Se prevented the incorporation of $\mathrm{Sn}$ into ALA dehydratase and as a result ALA dehydratase activity was similar to control values. It is considered that the chemical form of Sn might show a difference between after injection of $\mathrm{Sn}$ alone and after $\mathrm{Sn}$ injection together with selenite. Therefore, the affinity of Sn to proteins might be different.

It is known that the bone marrow is the main erythropoietic organ. Tin concentrations in bone marrow cells were $38.8 \mu \mathrm{g} / \mathrm{g}$ dry weight in group B (Sn) and $23.3 \mu \mathrm{g} / \mathrm{g}$ dry weight in group D (Sn plus Se). These values suggest that Se injected together with $\mathrm{Sn}$ prohibits incorporation of $\mathrm{Sn}$ into bone marrow cells. This is similar to the results in erythrocytes described previously.

The recoveries of $\mathrm{Sn}$ from the column were $85 \%$ and $102 \%$ and those of ALA dehydratase activity were $75 \%$ and $102 \%$ for groups $B(\mathrm{Sn})$ and $\mathrm{D}(\mathrm{Sn}$ and Se) respectively. The recoveries of Se from the column were $100 \%$ for group $\mathrm{C}(\mathrm{Se})$ and $85 \%$ for group D.

This research was supported by a grant in aid for Scientific Research, The Ministry of Education, Science and Culture, Japan, and The Araki Grants.

Requests for reprints to: Momoko Chiba, MD, Department of Hygiene, Juntendo University School of Medicine, 2-1-1 Hongo, Tokyo 113, Japan.

1 Schwarz K, Milne DB, Vineyard E. Growth effects of tin compounds in rats maintained in a trace element controlled environment. Biochem Biophys Res Commun 1970;40:22-9.

2 Chiba M. Determination of tin in biological materials by atomic absorption spectrometry with a graphite furnace. J Anal Toxicol 1987;11:125-30.

3 Ogoshi K, Kurumatani N, Aoki Y, et al. Disease in compressive strength of the femoral bone in rats administered stannous chloride for a short period. Toxicol Appl Pharmacol 1981, 58:331-2.

4 Chiba M, Ogihara $K$, Kikuchi $M$. Effect of tin on porphyrin biosynthesis. Arch Toxicol 1980;45:189-95.

5 Chiba M, Fujimoto N, Kikuchi M. Protective effect of selenium on the inhibition of erythrocyte 5-aminolevulinate dehydratase activity by tin. Toxicol Lett 1985;24:235-41.

6 Fritsch P, De Saint Blanquat G, Derache R. Nutritional and toxicological study of rats fed a diet containing tin. Toxicology 1977;8:165-75.

7 Anderson PM, Desnick RJ. Purification and properties of $\delta$ aminolevulinate dehydrase from human erythrocytes. $J$ Biol Chem 1979;254:6924-30.

8 Haeger-Aronsen B, Abdulla M, Fristedt BI. Effect of lead on $\delta$ aminolevulinic acid dehydratase activity in red blood cells. Arch Environ Health 1971;23:440-5.

9 Chiba M, Kikuchi M. Influence of the administration of lead and other metals on the activity of $\delta$-aminolevulinic acid dehydrase with and without heat treatment. Japan Journal of Industrial Health 1974;16:226-7.

10 Tohyama C. Distribution of mercury and selenium in mice after injection of methylmercuric chloride and sodium selenite. Japan Journal of Industrial Health 1975;17:491-9.

11 Hill C. Reversal of selenium toxicity in chicks by mercury, copper, and cadmium. J Nutr 1974;104:593-8.

12 Chiba M, Fujimoto N, Oyamada N, et al. Interactions between selenium and tin, selenium and lead, and their effects on ALAD activity in blood. Biol Trace Elem Res 1985;8:263-82.

13 Watkinson $\mathrm{JH}$. Fluorometric determination of selenium in biological material with 2,3-diaminonaphthalene. Anal Chem 1966;38:92-7.

14 Dickson RC, Tomlinson RH. Selenium in blood and human tissues. Clin Chim Acta 1967;16:311-21.

15 Chiba $M$. Biological interactions between selenium and tin, and selenium and lead. In: Abdulla M, Dashti H, Sarker B, et al, eds. Metabolism of minerals and trace elements in human disease. London: Smith-Gordon Co Ltd, 1989;147-56.

Accepted 2 September 1991 